COMENTARIOS DE JURISPRUDENCIA

\title{
La necesidad de la pena como criterio determinante en la procedencia de la regla del artículo 103 del Código Penal en ilícitos de lesa humanidad: Comentario a la sentencia 34.447-2016 de la Corte Suprema
}

\author{
The need of sentence as decisive criteria in the proceeds of the rule \\ of the article 103 of the penal code in crimes against humanity: \\ Commentary on Supreme Court ruling 34.447-2016
}

\section{Francisco Javier PARRA}

Abogado, Chile

\begin{abstract}
RESUMEN En la Corte Suprema existe un intenso debate sobre la procedencia de la regla del artículo 103 del Código Penal en los delitos de lesa humanidad debido a la prohibición que el derecho penal humanitario internacional establece para la prescripción plena de aquellos ilícitos. La resolución de la controversia ha pasado por determinar si los fundamentos de la prescripción, especialmente el de "necesidad de la pena», son diversos o análogos a los de la llamada «media prescripción».
\end{abstract}

PALABRAS CLAVE Media prescripción, prescripción gradual, delitos de lesa humanidad, necesidad de la pena, merecimiento de pena.

ABSTRACT In the Supreme Court an intense debate exists on the proceeds of the rule of the article 103 of the Penal Code in the crimes against humanity because of the prohibition that the Humanitarian International Criminal Law establishes for the full prescription of those crimes. The resolution of the controversy has happened for determining if the foundations of the prescription, specially of «need of sentence», are diverse or analogous to those of the so-called «half prescription».

KEYWORDS Half prescription, gradual prescription, crimes against humanity, need of sentence, merit of sentence. 


\section{Introducción}

El derecho penal humanitario internacional veda la posibilidad de declarar la prescripción, tanto de la pena como de la acción penal, en los delitos denominados como

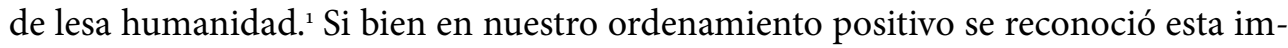
prescriptibilidad al instaurarse la Reforma Procesal Penal, ${ }^{2}$ con el establecimiento de la prohibición de decretar el sobreseimiento definitivo en este tipo de delitos, según lo previsto en el inciso final del artículo 250 del Código Procesal Penal, ${ }^{3}$ la Corte Suprema ha unificado su criterio en orden a reconocer esta imprescriptibilidad de manera reciente, ${ }^{4}$ tras años de debate y fallos en uno u otro sentido. ${ }^{5}$

Este reconocimiento del máximo tribunal se ha hecho de dos formas: por una parte, hay resoluciones que entienden que la prohibición del derecho penal humanitario internacional en los ilícitos de lesa humanidad es absoluta, extendiéndose también sobre la regla prevista en el artículo 103 del Código Penal; ${ }^{6}$ por otra, resoluciones, como el fallo que comentamos, entienden que si bien es necesario condenar a los responsables por estos crímenes, como ha transcurrido un considerable tiempo entre la perpetración del hecho punible y el juzgamiento de los delincuentes, dicho castigo debe ser morigerado a través de la concurrencia de la llamada «media prescripción»,

1. Ya reconocida por el Estatuto de Nüremberg (Matus Acuña, 2005: 216). Y de modo expreso en la Convención sobre la Imprescriptibilidad de los Crímenes de Guerra y de los Crímenes de Lesa Humanidad, adoptada y abierta a la firma, ratificación y adhesión por la Asamblea General en su resolución 2391 (XXIII), de 26 de noviembre de 1968, en su artículo I, letra b. Para una descripción detallada del alcance de esta categoría delictiva, tanto en el ámbito internacional como en el interno, véase Cárdenas Aravena (2014: 169-189).

2. Sin perjuicio de entender que, antes, como lo señala Matus Acuña, ya existía esta imprescriptibilidad en nuestro ordenamiento como consecuencia del reconocimiento de las normas de derecho internacional: «Sin embargo, desde el punto de vista del derecho penal internacional, el que Chile haya suscrito o no esta Convención no es oponible a la norma de ius cogens que establece ese carácter a esta clase de delitos» (2005: 217).

3. En otros ordenamientos, la imprescriptibilidad ha sido consagrada positivamente en los códigos punitivos: así lo dispone el artículo 131 número 4 del Código Penal español y el parágrafo 78 del Código Penal alemán.

4. Una panorámica completa de los hitos judiciales en la materia puede verse en Nogueira (2015: 580).

5. Para una revisión de la ya superada discusión, véase Bernales Rojas (2007: 245- 265).

6. Esta norma contiene el instituto comúnmente llamado como «media prescripción» o "prescripción gradual» y que, del tenor del artículo 103 del Código Penal, opera del modo que sigue: «Si el responsable se presentare o fuere habido antes de completar el tiempo de la prescripción de la acción penal o de la pena, pero habiendo ya transcurrido la mitad del que se exige, en sus respectivos casos, para tales prescripciones, deberá el tribunal considerar el hecho como revestido de dos o más circunstancias atenuantes muy calificadas y de ninguna agravante y aplicar las reglas de los artículos 65, 66, 67 y 68 sea en la imposición de la pena, sea para disminuir la ya impuesta. [...] Esta regla no se aplica a las prescripciones de las faltas y especiales de corto tiempo». 
y que culmina, en la mayoría de los casos, en el cumplimiento de las penas en alguna de las formas sustitutivas de la Ley 18.216.7 A esta última postura jurisprudencial se le ha denominado «Doctrina Dolmetsch». ${ }^{8}$

El debate, a la usanza de la polémica sobre la exigencia de un examen de pureza como elemento de los tipos penales de la Ley de Drogas, ${ }^{9}$ ofrece soluciones diversas según quiénes sean los ministros o integrantes que en un día determinado conformen la Sala Penal de la Corte Suprema. ${ }^{10}$

Independiente del calificativo dado a la regla del artículo 103 del Código Penal ${ }^{11}$

7. Cf. Viera-Gallo y Lübbert (2012: 112) y Silva Alliende (2011: 133). Esta es la conclusión que se señala en Centro de Derechos Humanos (2009: 39). En efecto, la fórmula de la llamada "media prescripción» permite fijar la pena por debajo del límite máximo que establece la Ley 18.216 para acceder a alguna de sus penas sustitutivas.

8. Ya que su elucubración se atribuye al actual presidente de la Corte Suprema, Hugo Dolmestch Urra. Como señala Matus Acuña (2012), esta doctrina fue «el producto de una larga evolución jurisprudencial: mientras hasta antes del retorno a la democracia en 1990 y durante buena parte de la década siguiente los tribunales aplicaban a estos casos el Decreto Ley de Amnistía, sobreseyendo las causas o absolviendo a los acusados, con el cambio de Gobierno, de los integrantes de la Corte Suprema y la pérdida de poder político del mundo militar, lentamente se fue, primero, obligando a investigar las causas antes de aplicar la amnistía o la prescripción ('doctrina Aylwin'); luego, a sancionar como 'secuestros permanentes', sin amnistía ni prescripción, delitos de secuestro que se sabía habían terminado en la muerte con ocultamiento de cadáver de las víctimas, fingiendo que se encontraban todavía secuestradas; para pasar a sancionar, igualmente, casos de ejecuciones políticas, donde no era posible la ficción de que el ejecutado se encontraba todavía 'secuestrado permanentemente'. Entre medio, el caso Almonacid llevó a una condena al Estado de Chile por no sancionar a los autores de su muerte, declarando la Corte Interamericana de Justicia que esta clase de delitos no podría ni amnistiarse ni prescribir y que el Estado debía anular el Decreto Ley de Amnistía e impedir legalmente la aplicación de la prescripción. [...] Sin embargo, el Congreso no fue ni ha sido capaz de resolver este conflicto, el cual se trasladó a la Corte Suprema. En este contexto, la 'Doctrina Dolmestch' apareció como una suerte de 'compromiso' entre los afanes de 'justicia absoluta' y 'perdón absoluto', permitiendo una condena ('justicia'), pero otorgando al condenado alguno de los beneficios de la Ley 18.216, a que se puede acceder admitiendo la rebaja de la media prescripción ('perdón')». Esta etapa es denominada como un «proceso de impunidad parcial» (González y otros, 2014: 331).

9. La Corte Suprema ha señalado que la pureza de la droga no es un elemento del tipo penal en los siguientes fallos: 5.088-16, del 17 de marzo de 2016; 2533-16, del 15 de marzo de 2016; 874-2016, del 25 de febrero de 2016; 172-16, del 23 febrero 2016; 36.502-15, del 28 enero 2016; y 37.797-15, del 26 de enero de 2016. Por el contrario, en el mismo periodo de tiempo, el máximo tribunal dijo que la pureza de la droga sí es un elemento del tipo penal (de modo que, si no está determinada, debe absolverse a los acusados), en los fallos siguientes: 35.557-15, del 18 de enero de 2016; 37633-15, del 27 de enero de 2016; y 36.837-2015, del 28 de enero de 2016 .

10. Transgrediéndose gravemente el principio constitucional de igualdad ante la ley, como lo indica Matus Acuña (2012).

11. En doctrina, Yuseff Sotomayor (2009: 161) estima que la media prescripción es una especie de prescripción. Así también lo declaran, para zanjar la controversia objeto de debate en la Corte Suprema, Nogueira (2015: 581) y Guzmán Dalbora (2009: 68). En nuestra jurisprudencia, la posición opuesta a la 
—-morigerante especial, regla de determinación de la pena-, lo cierto es que tanto el voto de mayoría como el de minoría entienden que se trata de una institución diversa a la prescripción "plena», difiriendo en cuáles son los fundamentos de cada entidad, de guisa tal que, si se estima que éstos son distintos se opta por admitir la llamada «prescripción gradual» en los delitos de lesa humanidad. Por el contrario, si se considera que comparten los mismos principios, se desestima su procedencia en estos ilícitos o, lo que es igual, se considera que la regla del artículo 103 del Código Penal se encuentra dentro del radio prohibitivo previsto por el derecho penal humanitario internacional.

En este comentario efectuaré un análisis crítico de los fundamentos dados por el voto mayoritario, ${ }^{12}$ con especial énfasis en el sistema estructural de la llamada «media prescripción» en nuestro ordenamiento positivo ${ }^{13} \mathrm{y}$ del principal fundamento esgrimido por el máximo tribunal para resolver la controversia: la «necesidad de pena».

\section{Los hechos y el derecho aplicado}

\section{a) Hechos que se dieron por probados y recursos deducidos}

El día 19 de septiembre de 1973, en horas de la tarde, un funcionario de la Subcomisaría Villa Moderna, que se mantenía en labores de vigilancia en la Empresa Airolite, fue informado por el dueño y recién designado delegado del Gobierno Militar Bernardo Dow Trewik Slomka que se llevaría a efecto una reunión en la Fábrica, ubicada en la calle Panamericana Norte 4.251, entre él y los administradores anteriores al pronunciamiento militar, el interventor del Gobierno de la Unidad Popular, don Oscar Pizarro Vicencio, y el asesor legal, el egresado de derecho don Guillermo Osvaldo Vallejo Ferdinand, con el objeto de que estos últimos hicieran entrega de

\footnotetext{
alcanzada en el fallo que comentamos, consigna, en el voto en contra en la sentencia de la Corte Suprema rol 13.149-2015, del 21 de junio de 2016, también de autoría del ministro Juica, que: «ya que al revés de lo que se declara en esta sentencia de casación, la norma del artículo 103 del Código Penal no constituye por sí sola una minorante o mitigante de responsabilidad criminal, sino que objetivamente es un factor de reducción de la pena, basado exclusivamente en la existencia de un hecho punible que admite la prescripción de la acción penal o de la pena y por ello se supone, aunque no concurran, la existencia de dos o más circunstancias atenuantes y prescinde, al contrario de agravantes, a pesar de estar establecidas».

12. La sentencia 34.447-2016 fue pronunciada por la Segunda Sala integrada por los ministros Milton Juica, Carlos Künsemüller, Lamberto Cisternas, Manuel Valderrama, y el abogado integrante Jean Pierre Matus Acuña. La mayoría, en lo que dice relación con la procedencia del artículo 103 del Código Penal en los delitos de lesa humanidad correspondió a los ministros Cisternas, Künsemüller y al abogado Matus Acuña, y el voto en contra a los ministros Juica y al abogado Valderrama.

13. Algunos aspectos analíticos sobre la procedencia en los delitos de lesa humanidad de la regla del artículo 103 del Código Penal desde la perspectiva del derecho interno pueden encontrarse en Guzmán Dalbora (2009: 68).
} 
documentación y dinero que pertenecía a la empresa, conforme se había acordado el día anterior.

El funcionario policial comunicó a su unidad la realización de la reunión y hasta el lugar concurrió personal de Carabineros dependiente de la Quinta Comisaría de Conchalí, quienes procedieron, sin orden legal que lo justificase, a detener a Pizarro y Vallejo, subirlos a un vehículo y luego trasladarlos hasta las dependencias de dicha unidad policial, ubicada en calle Hipódromo Chile 1.025.

De esta circunstancia fue informada, en la misma tarde de ese día, la pareja del interventor Pizarro, quien a su vez comunicó el hecho a la cónyuge de Vallejo Ferdinand; y ésta, al día siguiente, lo visitó, acompañada de un abogado, informándose por los funcionarios policiales que ambos detenidos serían trasladados al Estadio Nacional.

En virtud de lo informado en la unidad policial, la cónyuge de Vallejo Ferdinand intentó ubicarle en el Estadio Nacional, sin resultados positivos, por lo que inició una búsqueda que culminaría en el Servicio Médico Legal, cuando se enteró que en ese lugar se hallaba el cuerpo sin vida de su marido, el que había sido encontrado en la vía pública, en las inmediaciones de la Plaza Chacabuco, el día 22 de septiembre de ese mismo año, con numerosas heridas de bala.

Tales sucesos fueron calificados como constitutivos del delito de homicidio calificado, previsto y sancionado en el artículo 391 número 1 del Código Penal, ocurrido entre el 19 y el 22 de septiembre de 1973, con las calificantes de premeditación conocida y alevosía.

La sentencia condenatoria se dictó el día 6 de mayo de 2015, sancionando, como autores del ilícito, a los imputados José Alejandro González Inostroza, Antonio Aladino Villegas Santana y Andrés Leopoldo Flores Sabelle, a cuatro años de presidio menor en su grado máximo, debido al reconocimiento de la llamada «media prescripción» en beneficio de los sentenciados. Además, dichas penas fueron sustituidas por las de libertad vigilada intensiva por el término de cuatro años. Asimismo, se absolvió al inculpado Bernardo Dow Trewik Slomka de los cargos que en calidad de cómplice del homicidio se dirigieran en su contra.

En la segunda instancia, por resolución del 28 de abril de 2016, la Corte de Apelaciones de Santiago revocó la sentencia en la parte que condenaba al encartado Villegas Santana como autor del ilícito referido, resolviendo en su lugar que lo absolvía de aquella imputación, confirmando en lo demás el fallo de primer grado.

Luego, se dedujeron recursos de casación en la forma y en el fondo ante la Corte Suprema por los diversos intervinientes, pero, en lo que interesa a este comentario, resulta relevante el segundo apartado de la casación en el fondo interpuesta por la querellante de autos y el segundo capítulo de la casación en el fondo deducida por el Programa de Continuación Ley 19.123 del Ministerio del Interior y Seguridad Pública.

En cuanto a la parte querellante, su segunda sección de reproches se asiló en la 
causal primera del artículo 546 del Código de Procedimiento Penal, porque la sentencia impugnada habría impuesto una pena menos grave que la que debió aplicar, al hacer procedente el instituto de la denominada «prescripción gradual», infringiendo con ello los artículos 5 de la Constitución Política de la República, 1.1 y 2 y 8 de la Convención Interamericana de Derechos Humanos, 4 número 2 de la Convención contra la Tortura y Otros Tratos o Penas Crueles, Inhumanos o Degradantes, 2 número 2 de la Convención Interamericana sobre Desaparición Forzada de Personas, 131 de la Convención de Ginebra, 27, 53 y 54 de la Convención de Viena sobre Derecho de los Tratados, y 69, 103 y 141 del Código Penal. La imposición de una pena tan benigna se debió, según la actora, fundamentalmente a la inadecuada aplicación de la regla del artículo 103 del Código Penal, ya que ello no procedía por tratarse de un delito de lesa humanidad. Señaló que no existe norma del ius cogens que reconozca la procedencia de dicha institución, ya sea total o a medias, como lo hizo la sentencia, ya que ambos institutos se basan en el transcurso del tiempo. Finalmente, indicó que rebajar la pena significa desnaturalizar el concepto de castigo y menoscabar las obligaciones internacionales suscritas sobre la materia por el Estado de Chile.

Por su parte, el segundo capítulo de la casación en el fondo deducida por el Programa de Continuación Ley 19.123 del Ministerio del Interior y Seguridad Pública denuncia que el fallo hizo una errónea aplicación de lo dispuesto en el artículo 103 del Código Penal, configurando la causal primera del artículo 546 del Código de Procedimiento Penal, en relación a los artículos 1 y 15 número 1 del Código Penal, infringiendo, además, los artículos 68 y 69 del Código Penal, debido a que el instituto de la llamada «prescripción gradual» no resultaría procedente por tratarse de un delito de lesa humanidad, lo que excluiría cualquier compensación racional, sin que el sentenciador pueda utilizar la norma como fundamento para concurrir a la rebaja de pena. Asimismo, agregan que si bien la aplicación de la morigerante resulta discrecional según lo disponen los artículos 65, 66, 67 y 68 del Código Penal, ella no es atendible en estos autos, ya que, de hacerlo, se infringe el principio de proporcionalidad de la pena, conforme al cual se debe aplicar al responsable una sanción equivalente al daño causado.

\section{b) El derecho aplicado por la Corte Suprema}

La resolución del máximo tribunal, en lo tocante al aspecto comentado, encuentra sus motivaciones en los considerandos decimocuarto, decimoquinto y decimosexto del fallo, a saber:

Decimocuarto. Que sobre el asunto en estudio y sin perjuicio de los fundamentos que se han expuesto en numerosas sentencias para desestimar la concurrencia de la prescripción de la acción penal como causal de extinción de la responsabilidad criminal en hechos que constituyan delitos de lesa humanidad, es lo cierto que el 
instituto de la prescripción gradual constituye una minorante calificada de responsabilidad, cuyos efectos inciden en la determinación del quantum de la sanción corporal, independiente de la prescripción, con fundamentos y consecuencias diferentes. Así, aquélla descansa en el supuesto olvido del delito, en razones procesales y en la necesidad de no reprimir la conducta, lo que conduce a dejar sin castigo el hecho criminoso, en cambio la morigerante halla su razón de ser en lo ajeno a los fines preventivos que puede resultar una pena excesivamente severa para hechos ocurridos largo tiempo atrás, pero que no por ello deben dejar de ser irremediablemente sancionados, aunque resulta de su reconocimiento una pena menor. De este modo, en los casos como el presente, aunque el decurso del tiempo desde la comisión del ilícito se haya prolongado en exceso, no provoca la desaparición por completo de la necesidad del castigo y nada parece oponerse a que los tribunales recurran a esta atenuación de la sanción, pues el lapso transcurrido atempera, en concepto del propio legislador, el rigor de la represión.

Decimoquinto. Que, en definitiva, la prescripción gradual conforma una mitigante muy calificada cuyos efectos inciden sólo en la magnitud de la pena - la que subsiste y excluye, por tanto, a la impunidad-y por su carácter de regla de orden público, su aplicación es obligatoria para los jueces, en virtud del principio de legalidad que gobierna al derecho punitivo. Tampoco se advierte ninguna restricción constitucional, legal, de derecho convencional internacional ni de ius cogens para su aplicación, desde que aquellas reglas sólo se limitan al efecto extintivo de la responsabilidad criminal. Entonces, no se divisa razón que obstaculice considerarla en este caso como atenuante para mitigar la responsabilidad criminal que afecta a los encausados González Inostroza y Flores Sabelle, teniendo en cuenta para ello que se estableció como data de la muerte de Guillermo Osvaldo Vallejo Ferdinand entre el 19 y el 22 de septiembre de 1973, fechas ciertas que permiten precisar el inicio del término que es necesario considerar para la procedencia de la institución que se analiza.

Décimosexto. Que del estudio de los antecedentes fluye entonces que el lapso requerido para la procedencia de la institución cuestionada por los impugnantes ha transcurrido con creces, y como se trata de una norma de orden público los jueces del fondo han debido aplicarla, al ser claramente favorable a los procesados, de manera que al hacerlo no han incurrido en la causal de invalidación propuesta, por lo que también deberán rechazarse los recursos de casación en el fondo basados en este capítulo de alegaciones.

\section{Apreciación crítica del voto mayoritario}

La posición que acepta la procedencia de la denominada «media prescripción» en los delitos de lesa humanidad ${ }^{14}$ entiende que la prohibición que el derecho penal hu-

14. Esta sería la tesis mayoritaria en la jurisprudencia del máximo tribunal, como lo señala Fernández Neira (2010: 74). 
manitario internacional establece sobre la prescripción en esta clase de crímenes no comprende a la regla del artículo 103 del Código Penal, ya que ésta no sólo es un instituto diverso a la primera, sino que, además, comparten fundamentos distintos, que, en el caso de la llamada «media prescripción», no contravendrían el sentido de la restricción aludida.

Como se aprecia de los considerandos transcritos, el voto de mayoría ${ }^{15}$ señala que los efectos de la regla del artículo 103 del Código Penal inciden en la determinación del quantum de la sanción corporal, independiente de la prescripción, con fundamentos y consecuencias diferentes; luego declara, como fundamento de la prescripción, que ésta descansa en el supuesto olvido del delito, en razones procesales y en la necesidad de no reprimir la conducta, lo que conduce a dejar sin castigo el hecho criminoso y de la llamada «media prescripción», que ésta halla su razón de ser en lo ajeno a los fines preventivos que puede resultar una pena excesivamente severa para hechos ocurridos largo tiempo atrás, pero que no por ello deben dejar de ser irremediablemente sancionados, aunque resulta de su reconocimiento una pena menor; agrega, respecto al efecto del tiempo en los delitos de lesa humanidad, que éste no provoca la desaparición por completo de la necesidad del castigo y nada parece oponerse a que los tribunales recurran a esta atenuación de la sanción, pues el lapso transcurrido atempera, en concepto del propio legislador, el rigor de la represión.

\section{La independencia entre la prescripción y la regla del artículo 103 del Código Penal}

La sentencia declara que los efectos del artículo 103 del Código Penal inciden en la determinación de la sanción con independencia de la prescripción, ya que cada una tiene fundamentos y consecuencias diversas. Sin analizar en este acápite lo relativo a dichos fundamentos y consecuencias disímiles entre ambos institutos, la autonomía absoluta que el voto mayoritario atribuye a ambas instituciones implica que a la regla del artículo 103 del Código Penal no le serían aplicables las restantes normas que el estatuto prescriptivo de nuestro Código Penal contempla respecto de la prescripción: si la llamada «media prescripción» es independiente de la prescripción, en el sentido de que a la primera no le afecta la prohibición que el derecho penal humanitario internacional hace pesar sobre la segunda, entonces a aquélla tampoco le influirían las reglas accesorias del sistema, como la suspensión e interrupción del cómputo (artículo 96 del Código Penal), la llamada "prescripción extraordinaria» (artículo 100 del Código Penal) ni la forma especial de iniciar el término en ciertos delitos sexuales cometidos contra menores de edad (artículo 369 quáter del Código Penal). Un análisis casuístico fuerza a concluir que esta posición no puede ser aceptada.

15. De los ministros Cisternas, Künsemüller y del abogado integrante Matus Acuña. 


\section{La interrupción del artículo 96 del Código Penal}

La interrupción del artículo 96 del Código Penal se encuentra asociada a la comisión de un nuevo delito durante el plazo de prescripción. El efecto de la comisión de este nuevo ilícito es reiniciar el cómputo del término interrumpido desde cero. ${ }^{16} \mathrm{La}$ independencia absoluta propuesta por el fallo comentado entre la prescripción plena y la llamada «media prescripción» implica, en el caso del artículo 96 del Código Penal, entender que la comisión de un nuevo delito durante el curso de un término prescriptivo no produce efecto alguno en el plazo de la denominada «media prescripción», afectando solamente el curso de la prescripción "plena». Siguiendo esta premisa, entonces, resultaría posible que ante la comisión de un delito durante un curso prescriptivo se produzca una separación o «duplicación» de términos: uno, que es interrumpido por el nuevo ilícito y que se reinicia con éste (que es el plazo de la prescripción «plena»), y otro, que no es afectado por el nuevo delito y que continúa corriendo sin ninguna clase de restricción (el término de la «media prescripción»). Por su parte, el plazo de la llamada «media prescripción», por mandato del artículo 103 del Código Penal, es la mitad del correspondiente a la prescripción «total»: si se acepta que a la denominada «media prescripción» no le resulta aplicable la interrupción y el reinicio del artículo 96 del Código Penal, entonces, ante la comisión de un nuevo delito, puede alcanzarse la «media prescripción» en un término que no será la mitad de aquél en que se complete el de la prescripción «plena».

Lo anterior resulta claro al llevar estos planteamientos a un ejemplo: un sujeto el día 1 de enero de 2000 comete un delito de robo con violencia (robo 1) que, de conformidad a la relación entre el artículo 433 del Código Penal y 94 del mismo Código, tiene un plazo de prescripción de diez años. Luego, el 29 de diciembre de 2009 vuelve a cometer el mismo delito (robo 2), interrumpiéndose el curso de la prescripción y reiniciándose desde cero. En esta hipótesis, el plazo de prescripción «total» del robo 1 (si no se vuelve a interrumpir) se completará el 29 de diciembre de 2019 (en conjunto con el del robo 2).

Si se estima que entre ambos institutos existe una autonomía absoluta, entonces, en el ejemplo propuesto, en el robo 1 se habrá adquirido la media prescripción el día 2 de enero de 2005, esto es, al transcurrir al menos la mitad del término de prescripción «total» original, pues el cometimiento de un delito posterior (robo 2) no surtiría efecto alguno, esto es, no lo habría interrumpido ni lo habría reiniciado desde cero. Sin embargo, la prescripción total del robo 1 solo se alcanzará, como se dijo, el 29 de diciembre de 2019. Y allí, entonces, se rompe la armonía del sistema, pues la llamada «media prescripción» se habrá alcanzado en un plazo muy inferior a la mitad del que finalmente corresponderá a la prescripción «plena» del delito.

16. Al decir de Guzmán Dalbora (2003: 472), el término comienza a correr ex novo et ex integro. 
Por el contrario, si se entiende que ambas instituciones se encuentran conectadas de forma tal que a la llamada «prescripción gradual» le son aplicables todas las restantes normas del estatuto prescriptivo, en el caso propuesto no sería admisible la concurrencia de esta regla, pues al iniciarse nuevamente el cómputo con la comisión de cada infracción nueva, este reinicio también sería aplicable a la institución del artículo 103 del Código Penal: de este modo, la llamada «media prescripción» del robo 1 (suponiéndose que el delincuente no vuelve a cometer nuevamente otro delito) sólo se configurará después del día 30 de diciembre de 2014, es decir, desde exactamente la mitad del término que corresponde a la prescripción «plena»; en ambos casos el cómputo corre reiniciado desde la fecha de perpetración del robo $2 .{ }^{17}$

\section{La llamada «prescripción extraordinaria»}

Otro tanto sucede con la regla del artículo 100 del Código Penal, que contiene la llamada «prescripción extraordinaria», la cual considera como «medio día» los días del término en que el sujeto se ausenta del territorio nacional durante su curso. ${ }^{18}$ Usando el mismo ejemplo, si el sujeto que cometió el robo 1 huye, el mismo día de su perpetración, a la República Argentina, y es sorprendido en ésta el 1 de enero del año 2008, siendo extraditado de inmediato a nuestro país, aplicando la regla del artículo 100, su término prescriptivo transcurrido será el equivalente a la mitad de los días que estuvo fuera del territorio nacional (esto es, exactamente ocho años divididos por dos). Pues bien, si entendemos que no existe independencia absoluta entre la regla del artículo 103 del Código Penal y la prescripción «total», entonces en el ejemplo no podría ser reconocida en favor del delincuente la llamada «media prescripción», ya que habrían transcurrido cuatro años desde la perpetración del robo. Por el contrario, si se adscribe a la independencia absoluta entre los institutos, en el ejemplo el imputado será beneficiado con la llamada «media prescripción», ya que ésta se habrá alcanzado el 1 de enero de 2005, no obstante que en aquella fecha, para la prescripción «plena»,

17. Yuseff Sotomayor indica sobre el vínculo que la interrupción del artículo 96 del Código Penal genera entre la prescripción y la regla del artículo 103 del Código Penal, que «si este término se ha interrumpido por la comisión de nuevo delito, no puede sostenerse que, aunque haya transcurrido más de la mitad del término por la comisión de otro delito, pueda aplicarse el artículo 103. [...] La razón es preciso encontrarla en el hecho de que se hace referencia a los plazos de prescripción de la acción penal y de la pena, los que, como ya se ha dicho, se interrumpen por la comisión de nuevo delito. En ambos casos la interrupción hace desaparecer el tiempo transcurrido, el que, por ende, no puede producir ningún efecto» (2009: 165).

18. Se da cuenta de la resistencia que tuvo esta norma en el seno de nuestra comisión redactora, pero que terminó por imponerse debido a la idea general de establecer una prescripción para toda clase de supuestos, sin excepciones: «no convendría aceptar la prescripción en el extranjero, porque ella excluye la posibilidad de ser aprehendido, sin la cual no es justo que se extinga la responsabilidad penal del delincuente» (Rivacoba y Rivacoba, 1974: 498). 
sólo habrían transcurrido dos años y seis meses. La anomalía sigue si se hace la prognosis del momento en que el delincuente alcanzará la prescripción total del delito, lo que ocurriría, si no sale del país, el día 1 de enero de 2014, tiempo que casi triplica a aquel en que el delincuente se haría beneficiario de la llamada «media prescripción» siguiendo la línea de la independencia absoluta entre las instituciones.

\section{El dies a quo en ciertos delitos sexuales contra menores de edad}

Un problema similar se vislumbra en el caso de la norma prevista en el artículo 369 quáter del Código Penal, ${ }^{19}$ el cual, del mismo modo que en los ordenamientos que le sirvieron de inspiración, ${ }^{20}$ pospone el inicio del cómputo de la prescripción - dies a $q u o-$ de determinados delitos cometidos contra menores de edad, para que empiece a correr una vez que éstos alcancen la mayoría de edad, alterando la regla general prevista en el artículo 95 del Código Penal. ${ }^{21}$ En dichos presupuestos, siguiendo la

19. Incorporado por la Ley 20.207, del 31 de agosto de 2007. «Artículo 369 quáter. En los delitos previstos en los dos párrafos anteriores, el plazo de prescripción de la acción penal empezará a correr para el menor de edad que haya sido víctima, al momento que cumpla 18 años». Los delitos aludidos por el artículo recién transcrito son los previstos y sancionados en las siguientes normas del Código Penal: 361 , $362,363,365,365$ bis, 366,366 bis, 366 quáter, 366 quinquies, 367,367 bis y 367 ter.

20. En el Código Penal alemán, el parágrafo que sigue: «\$78 b: La prescripción se suspende: Hasta el cumplimiento de los dieciocho años de edad de la víctima en hechos punibles conforme al $\$ \$ 174$ a 174 c, 176 a 179, así como conforme al $\$ \$ 224$ y 226, cuando al menos una de las partes ofendidas a través del mismo acto sea una de las personas enumeradas en el \$225»; en el Código Penal de España, el artículo artículo 123.1, inciso segundo: «En la tentativa de homicidio y en los delitos de aborto no consentido, lesiones, contra la libertad, de torturas y contra la integridad moral, la libertad e indemnidad sexuales, la intimidad, el derecho a la propia imagen y la inviolabilidad del domicilio, cuando la víctima fuere menor de edad, los términos se computarán desde el día en que ésta haya alcanzado la mayoría de edad, y si falleciere antes de alcanzarla, a partir de la fecha del fallecimiento»; y en el Código Penal de la Argentina, artículo 63 incisos segundo y tercero: «En los delitos previstos en los artículos 119, 120, 124, 125, 125 bis, 128, 129 - in fine-, y 130 - párrafos segundo y tercero- del Código Penal, cuando la víctima fuere menor de edad la prescripción de la acción comenzará a correr desde la medianoche del día en que éste haya alcanzado la mayoría de edad. Si como consecuencia de cualquiera de los delitos indicados hubiera ocurrido la muerte del menor de edad, la prescripción de la acción comenzará a correr desde la medianoche del día en que aquél hubiera alcanzado la mayoría de edad».

21. Doctrinariamente, existen tres tipos de sistemas posibles de adoptar para determinar desde cuándo comienza a correr el término prescriptivo: el sistema alemán, donde el inicio del cómputo es el día en que se ejecute la acción, independiente del momento de verificarse el resultado típico - según lo reconocía el antiguo parágrafo $\$ 67$ del Código Penal alemán, hoy reformado- como se indica en Von Beling (2002: 160). Críticamente, Mezger (1958: 117); el sistema de la consumación, donde lo determinante para iniciar el cómputo es el momento en que se verifiquen todos los elementos del delito, que es el sistema de la mayoría de los ordenamientos actuales: Código Penal alemán, parágrafo $\$ 78^{a}$; Código Penal argentino, artículos 63 (acción penal, con regla especial para ciertos delitos contra menores de edad) y 66 (pena), Código Penal de Brasil, artículo 111 (con excepción de ciertos delitos, donde acoge 
independencia absoluta entre la prescripción y la llamada «media prescripción», que, en esta clase de delitos, implicaría asumir que no le resulta aplicable al delincuente la norma del artículo 369 quáter del Código Penal para efectos de entender que cumple con los requisitos del artículo 103 del Código Penal, sería perfectamente concebible, por tanto, que el agente se haga acreedor de la rebaja penológica de la llamada «media prescripción» cuando el término de la prescripción «plena» ni siquiera hubiese comenzado a correr, lo que se verificaría para el caso de alcanzarse, en los hechos, la mitad del plazo antes de que la víctima del delito sexual cumpliese los 18 años de edad.

\section{Los fundamentos de la prescripción y de la regla del artículo 103 del Código Penal}

Si bien doctrinariamente se han dado múltiples fundamentos a la prescripción penal $^{22}$ - de la acción y de la pena-, al menos con nuestro estatuto positivo de la ins-

el sistema del conocimiento), Código Penal colombiano, artículo 84, Código Penal de España de 1995, artículo 132 número 1 (con regla especial para ciertos delitos con víctimas menores de edad), entre otros tantos; y el sistema de la constatación o conocimiento del delito, donde el dies a quo lo marca la verificación del resultado típico, si el delito es conocido, o, en el caso opuesto, el día de su descubrimiento. La naturaleza de las víctimas obstaculizaría el descubrimiento del delito con anterioridad al vencimiento de su término prescriptivo. Por ello, la norma del artículo 369 quáter, introduce una excepción en el sistema de cómputo de la consumación recogido en el Código Penal, donde se ha terminado por acoger el sistema del conocimiento o constatación del delito, con el matiz de que el legislador pareciera presumir tal conocimiento o constatación - al menos en abstracto-, al momento en que la víctima alcanza la mayoría de edad. Lo dicho no obsta a que la circunstancia de la postergación que del inicio del cómputo hace el artículo 369 quáter del Código Penal pueda ser calificada como una suspensión de la prescripción, como afirma Cabezas (2013: 388-391). Sin embargo, esta conclusión no se condice con la naturaleza de la suspensión en nuestro ordenamiento. Un potente elemento en la argumentación del autor para la conclusión señalada se basa en el derecho alemán, donde efectivamente la suspensión tiene una naturaleza de impedimento u obstáculo a la persecución penal, pero ello pierde validez en nuestra legislación, donde la suspensión se verifica por el procedimiento dirigido contra el delincuente, en tanto que esa misma circunstancia en Alemania es una causal de interrupción; los fundamentos de los subsistemas de interrupción y suspensión en ambos ordenamientos son completamente diversos. Por su parte, resulta de interés la ratio que subyace a esta iniciativa legislativa y que consta en la historia de la ley, en el texto del proyecto original, primer trámite constitucional, del 3 de marzo de 2005: «Cuando un niño es víctima de un atentado sexual, la decisión de someter a la justicia al culpable, generalmente, va a ser de los adultos que se encuentran a su cargo, en su calidad de representantes legales. Estos adultos muchas veces deciden no deducir denuncia para evitar la estigmatización del niño y el trauma psicológico que eventualmente puede significar enfrentar un proceso judicial. Más grave aún resulta la situación en que los propios padres son los agresores porque evidentemente se tratará de esconder los hechos quedando el menor en total indefensión». También refuerza la tesis de adoptar una especie de sistema del conocimiento del delito con esta modificación, las aseveraciones realizadas en el texto de la Discusión General, primer trámite constitucional, del 6 de julio de 2005: «...es muy importante permitir que la menor o el menor, cuando llega a tomar conciencia de este abuso, pueda denunciarlo...» (el énfasis es nuestro).

22. Para una completa y crítica panorámica de los fundamentos de la prescripción, véase Ragués 
titución podemos dilucidar algunos aspectos que aclaran cuál es el justificativo para la renuncia punitiva al trascurrir el tiempo (Yuseff Sotomayor, 2009: 43). De acuerdo a lo señalado por el fallo que comentamos, la prescripción se encontraría fundada en razones procesales, en el olvido y en la ausencia de necesidad de pena.

\section{Las «razones procesales»}

Adjetivamente, si bien en el fallo comentado no se explicitan, en doctrina se conciben como justificativos de la prescripción a la dificultad probatoria para acreditar el ilícito (Welzel, 1976: 357), ${ }^{23}$ tanto para el persecutor, pues desaparecen las pruebas, ${ }^{24}$ como para el imputado, quien, en consecuencia, ve mermado su derecho a defensa para acreditar su inocencia, ${ }^{25}$ así como también por el derecho de los ciudadanos a un juzgamiento sin dilaciones excesivas (Ragués, 2004: 25). De conformidad al artículo 94 del Código Penal, que establece una escala gradual de plazos de prescripción asociada a la gravedad de los delitos que dicha disposición consagra, puede descartarse que en nuestro ordenamiento la prescripción se funde en la dificultad procesal para acreditar el delito: si ésta fuera la ratio de la prescripción, mal podrían existir plazos prescriptivos diversos, pues, la dificultad para probar el ilícito no varía por tratarse de un crimen, de un simple delito o de una falta. Por lo demás, este fundamento no puede explicar la prescripción de la pena, reconocida en el artículo 97 del Código Penal, donde el hecho está acreditado a tal punto que ya se ha impuesto una sanción punitiva sobre el culpable. Finalmente, aquél fundamento procesal relativo al derecho a ser juzgado dentro de un tiempo razonable no parece acertado - sólo tratándose de la prescripción de la acción penal, ya que en la de la pena no tiene cabida - cuando se piensa en un imputado que se encuentra en rebeldía; en tal caso, la dilación del procedimiento se debe precisamente a la acción del agente: es éste quien evita que el juzgamiento se verifique en un tiempo razonable. ${ }^{26}$

(2004: 24 y ss). Van Weezel (2007: 15) indica que el fundamento de la prescripción sería la necesidad de estabilización normativa de la sociedad. Para Muñoz Conde y García Arán (2004: 408), el fundamento sería fundamentalmente la seguridad jurídica.

23. Aunque agrega también la necesidad de pena. Por su parte, Jakobs (1997: 415 y 416) este fundamento adjetivo junto con otros materiales, adhiriendo a las denominadas «teorías mixtas» de la naturaleza de la prescripción, referidas también por Frister, quien, además, toma partido por los fundamentos adjetivos del instituto: «La doctrina hoy probablemente dominante acepta que ambos puntos de vista desempeñan un papel (la llamada teoría mixta de la prescripción). Pero, formalmente, la prescripción está configurada como impedimento procesal» (2011: 414).

24. Véase Garraud (1922: 543) y Roxin (1997: 991).

25. Esta habría sido la razón que tuvieron los griegos para establecer la prescripción, como señala Yuseff Sotomayor (2009: 23).

26. Para rechazar este fundamento, Ragués (2004: 26) señala que es la constatación de delitos imprescriptibles. Sin embargo, en tales ilícitos no puede buscarse fundamento a la prescripción, ya que ellos 


\section{El fundamento material del «olvido»}

El mismo artículo 94 del Código Penal permite descartar como fundamento de la prescripción a la idea del «olvido» aludida en el voto mayoritario, ${ }^{27}$ ya que no parece razonable que por un hecho arbitrario del legislador - la pena que asigna a un hecho- se refleje el tiempo en que la sociedad pierde la memoria y acepta la dimisión castigadora. Si bien podría contrargumentarse a lo anterior que el legislador ha hecho una valoración abstracta del tiempo en que la sociedad tardaría en olvidar los delitos, si al debate se añade, como se dijo antes, el evento que en nuestro sistema desencadena la interrupción de la prescripción - y que a su surgimiento el término se reinicia- que es la comisión de un nuevo delito, el «olvido» del primer hecho parece no justificar el reinicio del cómputo desde cero por la comisión de un ilícito posterior. Al menos en lo que respecta a nuestra interrupción de la prescripción, lo que se quiere para conceder la eximente es la observancia de una buena conducta por parte del delincuente, alejada de las infracciones penales: ${ }^{28}$ al cometerse una nueva contravención se considera que el agente aún necesita ser castigado por el primer hecho, pero con el plazo corriendo desde el inicio en la fecha del segundo ilícito. ${ }^{29}$

\section{El fundamento de la necesidad de la pena}

Ahora bien, estrictamente en lo relativo a la necesidad de la pena, debido a lo difuso y polisémico del concepto (Roxin, 1997: 981), resulta forzoso efectuar algunas consideraciones preliminares. Lo primero que cabe anotar es que este concepto suele ser asociado al de «merecimiento de pena». Mayoritariamente se ha entendido que el «merecimiento de pena» se adscribe a un juicio de desaprobación, en abstracto, que

precisamente, no prescriben. Por su parte, cabe señalar que tratándose de la duración misma de un procedimiento ya iniciado (que desencadena la suspensión del cómputo desde que el procedimiento se dirige contra el delincuente), el artículo 96 del Código Penal contempla, en casos de paralización por más de tres años, la reanudación del término prescriptivo como si nunca se hubiere suspendido.

27. Reconocido desde antiguo por la doctrina, como se indica en Garraud (1922: 543).

28. Antecedentes sobre este buen comportamiento exigido como requisito para la prescripción (que en nuestro ordenamiento se asume bajo la fórmula de la interrupción asociada a la comisión de un nuevo delito) figuran en el Código Bávaro, que disponía en su artículo 139, inciso segundo, segunda parte: «Y el culpable ha dado muestras durante ese tiempo de una buena conducta no interrumpida, será exento de toda pena». Igualmente, el Código del Cantón de Friburgo, en su artículo 80 letra d) exige requisitos adicionales respecto de la persona del delincuente para beneficiarse con la prescripción. Ambos artículos se encuentran íntegramente transcritos en Groizard y Gómez de la Serna (1872: 595 y 596). También lo prescribe el Código Penal Español de 1822, en su artículo 176.

29. Esta idea se vincula a la denominada «teoría de la enmienda» del delincuente, en cuya virtud el tiempo sin delinquir implica que éste ya se resocializó, lo que tiene relación, además, con la función de prevención especial que se asigna a la pena. 
recae sobre una determinada conducta: así sería, por ejemplo, una apropiación de una cosa mueble ajena sin la voluntad de su dueño, con ánimo de lucro y sin que concurran ciertas formas de fuerza especialmente penadas ni violencia o intimidación en las personas, es decir, un hurto en los términos del artículo 432 del Código Penal. Por ello, la ejecución de tal conducta desaprobada socialmente se encuentra asociada a una pena. Al contrario, la «necesidad de la pena» tendría lugar en aquellos casos en que, habiendo merecimiento de pena (siguiendo al ejemplo, cometiéndose un hurto), en el caso concreto resulta indispensable que dicha sanción se haga efectiva sobre el autor (Luzón Peña, 1995: 116), ${ }^{30}$ porque no existen otras clases de reacciones menos intensas que permitan reestablecer la vigencia de la norma vulnerada (Náquira, Izquierdo, Vial y Vidal, 2008: 23-24). ${ }^{31}$ Se trata, además, de principios que operan tanto en la fundamentación como en la limitación tanto de los elementos del delito como en otros requisitos de la pena no referidos al hecho..$^{32}$

Una segunda cuestión que cabe anotar consiste en desentrañar cuál es el vínculo entre la necesidad de la pena y la prescripción penal. Y, al respecto, surge la siguiente premisa: la acción penal y la pena prescriben porque ya no se necesita castigar a quien ha ejecutado un hecho merecedor de pena. ${ }^{33}$ Luego, surge la interrogante: ¿por

30. Morrillas (2013: 17) sostiene, aunque no expresamente, que la «necesidad de la pena» comprendería al «merecimiento de pena», ya que la primera «se proyecta en una doble dimensión: desde la conminación penal abstracta y desde la imposición y ejecución concreta. En la primera enlaza con la naturaleza de última ratio que al derecho penal se le asigna y con su carácter fragmentario, y con la de última ratio de la ultima ratio de la propia pena; en la segunda con la fijación individualizada de qué pena es innecesaria y perjudicial para la sociedad o para el propio delincuente».

31. Donde se indican, como reconocimientos positivos del principio de necesidad de pena (al menos de pena privativa de libertad) a los requisitos subjetivos de cada pena sustitutiva prevista en la Ley 18.216, como también al llamado «principio de oportunidad» del artículo 170 del Código Procesal Penal y a la «suspensión condicional del procedimiento» del artículo 237 del Código Procesal Penal. Al decir de Roxin: «pero una conducta 'merecedora de pena' sólo estará 'necesitada de pena' si se añade una necesidad preventiva de punición» (1997: 982).

32. «La teoría del delito se configurará así, como un sistema de reglas que permiten establecer con la mayor seguridad posible el sí o no de tales merecimiento y necesidad de pena. Y la teoría de la determinación de la pena como teoría de la concreción del contenido delictivo del hecho implicará, a la vez, el establecimiento del quantum de su merecimiento y necesidad (político-criminal) de pena» (Silva Sánchez, 2007: 6). Luzón Peña (1995: 119) agrega que ambos principios tienen puntos comunes con influencia recíproca.

33. Así, Merkel declara: «El trascurso del tiempo dificulta también el desempeño de las funciones propias del derecho penal sustantivo. La pena tardía no parece ser ya un medio de obtener los fines que con la pena se buscan. Cuanto más rápidamente siga la pena al delito, tanto mayor será su eficacia; cuanto más tiempo tarde en ser aplicada, tanto menos servirá para el logro de sus fines y tanto menos justa la considerarán el penado mismo y las personas que no hayan tenido participación en el delito. Éste, con sus efectos, va al cabo del tiempo a caer en el campo de la historia, desapareciendo de la esfera activa del presente. De esta manera, la actividad de la justicia, que se encamina a la compensación del mal 
qué se estima, entonces, que, transcurrido un tiempo, no es necesario castigar al delincuente? La respuesta pareciera ser la siguiente: porque se presume que trascurrido un tiempo determinado desde la perpetración del hecho (o desde la condena), la pena ya carece de utilidad. Pero la afirmación precedente requiere ser precisada. En atención al hecho que desata la interrupción de la prescripción en nuestro sistema (la comisión de un nuevo delito, según el artículo 96 del Código Penal), aparece la idea de prevención especial, en cuya virtud, con el transcurso del tiempo, desaparece la función resocializadora de la reacción penal. ${ }^{34}$ Pero esta «resocialización», como dijimos, no opera en concreto, sino que simplemente es presumida por el legislador, ya que no se requiere acreditar de modo alguno que el delincuente efectivamente se ha enmendado. ${ }^{35}$ Por ello, es posible que en el sistema adoptado por el Código Penal de 1874 se premie al criminal que depure su actuar delictual al punto de evitar ser descubierto, cuestión que no ocurría en los modelos legislativos adscritos a la prevención especial en concreto, donde se requería, junto al paso del tiempo, la observancia de una buena conducta ${ }^{36}$ que debía ser probada por el beneficiario.

Más allá de los inconvenientes del modelo adoptado, esta presunción de resocialización se reafirma con la escala de plazos prescriptivos que el artículo 94 del Código Penal asocia a la gravedad de los ilícitos perpetrados: un delito más grave presupone un mayor tiempo de demora en la resocialización del culpable. Como dije, los baremos de necesidad de pena - o necesidad de resocialización - en nuestros términos prescriptivos no son sino positivizaciones abstractas de conjeturas que, en los hechos, tienen una mayor probabilidad de ocurrir. Finalmente, lo que explica de mejor manera el fundamento de la necesidad de pena en la prescripción penal en nuestro ordenamiento es precisamente la existencia del artículo 103 del Código Penal.

producido, pierde su objeto. Los efectos psíquicos del delito, la intranquilidad y la alarma, el temor, el odio, la necesidad de dar satisfacción al ofendido, el ansia de retribución y pago, etcétera, etcétera [...], han desaparecido o no pueden ser alcanzados por la pena» (1910: 351 y 352).

34. Aunque abiertamente en contra de este fundamento para el sistema español, pero no así para los sistemas como el nuestro, está Ragués (2004: 35 y 36). La relación del fundamento de la prescripción con la interrupción de la misma es realizada por Antón Oneca en el siguiente tenor: «Se alega también que la permanencia de una conducta prolongada sin delinquir es signo de corrección espontánea y, de ausencia de peligrosidad; argumento que vale en nuestro derecho para la prescripción de la pena, pues ésta se interrumpe por la comisión de otro delito antes de completar el plazo de la prescripción [...] y para aceptar tal principio sería preciso admitir como causa de interrupción del plazo prescriptivo el nuevo delito, como nuestro Código establece para la prescripción de la pena, aunque no para la del delito» (1986: 612-613).

35. Lo dicho no implica que en el ordenamiento chileno sólo se atribuya a la pena el fin de prevención especial, sino que la prescripción penal sólo puede justificarse desde este fin de la pena y no de otro, como se indica más adelante.

36. Véase la nota 31. 


\section{La necesidad de la pena en la llamada media prescripción}

La génesis de la regla del artículo 103 del Código Penal recoge expresamente los argumentos dados en los acápites precedentes respecto de la prescripción, en forma disminuida. Esta norma fue concebida como una "prescripción gradual», ${ }^{37}$ cuyo fin no es sino «castigar menos» a medida que se acerca el fin del término prescriptivo. ${ }^{38}$ En la idea propuesta por Fabres, en la sesión 138 de la comisión redactora del Código Penal de 1874, contenida en la cuarta base que propuso para elucubrar el sistema prescriptivo chileno, ${ }^{39}$ se consignó lo que sigue:

que una vez transcurrida la mitad del tiempo de la prescripción haya prescripción gradual, imponiéndose al culpable una pena menor que la que le correspondería en otro caso, i disminuyéndose aún más a medida que se acerque el término de la prescripción. ${ }^{40}$

La idea Fabres era que se aplicara una pena menor de manera progresiva con el acercamiento del término de prescripción total. Sin embargo, ello no prosperó, sino que se optó por conceder la llamada «media prescripción» al verificarse la mitad del tiempo total de ésta (Rivacoba y Rivacoba, 1974: 498), principalmente por la dificultad de determinar con precisión cuál sería la pena que en definitiva le correspondería a un sujeto de acuerdo a esta menor necesidad de castigo. ${ }^{41}$

Entonces, históricamente, la institución fue concebida como una fórmula para enfrentar esta menor necesidad de castigo, que se solucionó a través de la concesión de a lo menos dos minorantes muy calificadas y ninguna agravante, pero que deja ver que la idea concretada apunta a una reducción gradual de la necesidad de la pena, hasta que ésta, una vez alcanzado el plazo total, se esfuma. Este criterio, lejos de separar a la prescripción de la media prescripción, la acerca. Mientras que en la primera se presume que ya no se requiere resocializar al delincuente, en la segunda se presume

37. Así se le suele llamar aún, entre otros, por Fernández Neira y Sferrazza (2009: 299-330), Garrido Montt (2009: 398) y Cury (2005: 804).

38. En plena armonía con lo que sostiene Jescheck (1993: 822), quien señala que el fundamento de la prescripción consiste en que la necesidad de la pena disminuye con el tiempo, hasta desaparecer. En el mismo sentido, Welzel: «por la paulatina extinción de la necesidad punitiva en virtud del trascurso del tiempo» (1976: 359). También Antón Oneca (1986: 612). Estos institutos compartirían fundamentos, según Guzmán Dalbora (2003: 483).

39. Yuseff Sotomayor (2009: 31); Rivacoba y Rivacoba (1974: 497 y 498), sesión presidida por el señor Reyes y con la asistencia de los señores Fabres, Gandarillas, Ibáñez, Manuel Rengifo, y el secretario Osvaldo Rengifo.

40. Véase Prieto (1955: 62) y Lazo (1915: 110).

41. Parece complejo -o derechamente imposible- adoptar una fórmula legislativa que contemple una reducción de pena progresiva, considerando años, meses y días desde que se alcanza la mitad del término hasta que se llega al total. 
que esta resocialización puede hacerse en menos tiempo, pues ya ha transcurrido la mitad del plazo que se exige para entender que el sujeto se ha enmendado, de modo que la pena a imponer - ostensiblemente menor-viene a completar esta reinserción total: la fórmula gráfica es, entonces, la siguiente:

En la prescripción plena: resocialización total = plazo de prescripción total. En la regla del artículo 103 del Código Penal: resocialización total = la mitad del plazo de prescripción total + pena ostensiblemente rebajada.

\section{Las otras funciones de la pena}

De manera sintética señalaré por qué los otros fines de la pena no justifican o fundamentan a la prescripción penal, ni plena ni parcial. La prevención general negativa no puede asociarse a la prescripción porque el efecto de esta última pugna con el objeto de la primera: mientras la imposición de la pena intimida a los ciudadanos a ejecutar una conducta ilícita, la existencia de la prescripción, esto es, que con el transcurso de tiempo el delito no será castigado, produce el efecto anverso..$^{42}$ La prevención general positiva, donde la pena reestablece la vigencia de la norma mediante un acto comunicativo, tampoco explica la prescripción, ya que en la eximente de responsabilidad el rol atribuido al tiempo no puede entenderse como un restablecimiento - ni aun presunto- de la vigencia de la norma: el acto comunicativo de pervivencia del derecho se verifica tanto si se sanciona al hecho de inmediato como si ello acontece mucho tiempo después (Ragués, 2004: 38). Finalmente, la función retributiva (Ragués, 2004: 38) de la pena puede descartarse de plano con la regla del artículo 96 del Código Penal, donde la comisión de un nuevo delito interrumpe la prescripción: en una teoría retributiva de la pena es indiferente para el castigo que el agente ejecute nuevas conductas delictivas o no ya que ésta no busca fin alguno (Politoff, Matus Acuña y Ramírez Guzmán, 2009: 503 y 504).

\section{Incidencia práctica de las consideraciones anteriores: la ruptura de los plazos}

Si hay algo que no cuestiona la sentencia que comentamos es que la prescripción «total» y la llamada «media prescripción» presentan, a lo menos, un aspecto compartido: la regla del artículo 103 del Código Penal está sujeta a un plazo y, dicho plazo, por disposición de la misma norma, es el equivalente a la mitad del previsto para la prescripción "plena» del delito de que se trate. ${ }^{43}$ Por ello, para resolver el enigma —de si procede o no esta regla en los ilícitos de lesa humanidad- es necesario corroborar

\footnotetext{
42. Mir Puig (2005: 751) indica que la prescripción halla, en su ámbito material, justificación en la ausencia tanto de prevención general como de prevención especial.

43. Por ello se ha dicho de la media prescripción que es una «institución funcionalmente parasitaria frente a la respectiva modalidad de ['plena'] prescripción», como sostiene Mañalich (2010: 234).
} 
si es posible cumplir con los requisitos que el propio artículo 103 del Código Penal exige para configurar la denominada «media prescripción». Así, entonces, deberá determinarse si en el caso concreto ha transcurrido al menos la mitad del término señalado para la prescripción "plena» del ilícito juzgado, de conformidad a la escala prevista para los delitos prescriptibles en el artículo 94 del Código Penal. Un análisis fáctico del caso juzgado por la sentencia que comentamos permite dar cuenta de la desfiguración que se produce en el sistema previsto por el artículo 103 del Código Penal como consecuencia de la divergencia originada en el fundamento de menor necesidad de pena que anota el voto mayoritario.

Los sentenciados de marras cometieron el delito entre los días 19 y 22 de septiembre del año 1973. Según el criterio de la Corte Suprema, al cabo de siete años y seis meses - suponiéndose que se trata de un delito que de no ser por su calidad de lesa humanidad, prescribiría en 15 años-, los delincuentes se hicieron acreedores de los beneficios de la llamada «media prescripción», es decir, entre el 19 al 22 de marzo de 1981, debido a que ya no sería «tan necesaria la pena». Pero no existe respuesta que explique por qué tal necesidad de pena no continuó disminuyendo - hasta decaera los quince años desde que se cometió el crimen (en el año 1988, y que es el duplo del término requerido para conferir la llamada «media prescripción»), ni a los 20 (en 1993), ni a los 25 (en el año 1998), ni a los 30 (en 2003), ni a los 35 (en 2008), ni tampoco a los 40 años (en febrero de 2013). No parece razonable que se justifique una necesidad de pena disminuida en los primeros siete años y seis meses contados desde la perpetración del hecho punible, pero que dicha necesidad no continúe reduciéndose con el transcurso de espacios temporales aún más prolongados que aquél. Ello se debe a que en un delito imprescriptible se ha asumido que la necesidad de pena no decae ${ }^{44} \mathrm{y}$, por ende, al aplicar este fundamento al caso concreto, la planificación aritmética del legislador - en que la mitad del término fija el momento en que se necesita un menor castigo- se rompe.

En síntesis, esta ausencia (en la prescripción plena) o diminución de necesidad de castigar (en la llamada «media prescripción») como fundamentos de los institutos, entendidas, como lo hace el voto mayoritario, sin ninguna clase de concatenación, deviene en la imposibilidad de cumplir con las exigencias legales para saber si pro-

44. Bascuñán Rodríguez afirma con bastante razón que el fundamento último de la imprescriptibilidad de los delitos de lesa humanidad -que en este comentario se da por sentada- es la impunidad: "Cuando la norma es supuestamente fundamental, y su infracción reiterada por el responsable de su vigencia queda impune, y esa impunidad es un factor relevante para su comisión, la expectativa normativa de intangibilidad del círculo de afectados actuales y potenciales se hace insignificante frente a las expectativas cognitivas de peligro de afectación. Frente a este fenómeno, una decisión legislativa posterior de prescindencia de la pena tiene inevitablemente el sentido de confirmación de la comunicación que portaban los delitos» (2007: 72) 
cede o no la regla del artículo 103 del Código Penal en un delito de lesa humanidad. ${ }^{45}$ Así, para saber si un ilícito puede prescribir, es imprescindible que se cumpla con el plazo que la ley o una norma jurídica superior establezca como suficiente para configurar dicha prescripción. ${ }^{46}$ Lo que al respecto dispone el derecho penal humanitario internacional es que estos ilícitos son imprescriptibles, esto es, carecen de un plazo, y éste nunca comienza a correr o, si se quiere, desde una perspectiva opuesta, dicho plazo es igual a infinito: pueden perseguirse punitivamente mientras exista un sujeto susceptible de ser castigado por el delito respectivo. Por su parte, para saber si el delito de lesa humanidad puede estar sujeto a la regla del artículo 103 del Código Penal, es necesario, primero, que no se haya alcanzado la totalidad del tiempo de prescripción del delito - cuestión que se verificaría siempre y en todo caso tratándose de un ilícito imprescriptible, lo que ya anuncia cierta distorsión de la figura del artículo 103 del Código Penal frente a esta clase de crímenes- y, segundo, se requiere, a su vez, saber si ha transcurrido o no, a lo menos, la mitad del tiempo de prescripción exigido para el injusto de que se trate. ${ }^{47}$ Como se habrá adivinado, un delito de lesa humanidad carece de plazo de prescripción y, por ende, el término nunca se habrá iniciado. De este modo, jamás podrá alcanzarse la mitad del plazo, ya que dicho plazo no corre ni existe. Dicho plazo equivale numéricamente a cero y la mitad de cero, también, aritméticamente es cero. Desde otra perspectiva, si el delito de lesa humanidad tiene un plazo de persecución indefinido, es decir, un plazo de prescripción que equivale a infinito, resulta imposible saber cuándo se cumple la mitad del tiempo requerido para la denominada «media prescripción», que no es otro que «medio infinito».

Aquí es donde el voto mayoritario presenta su principal falencia: luego de declarar que el delito perseguido es de lesa humanidad y, por tanto, imprescriptible (como se indicó, sin plazo de prescripción, el cual no se inicia ni tiene «mitad»), acto seguido, en el mismo considerando decimocuarto, establece la procedencia de la regla del artículo 103 del Código Penal y, de inmediato, en el considerando decimoquinto señala el momento en que el término empezó a correr: «teniendo en cuenta para ello que

45. Mañalich indica que la exclusión de la media prescripción en los delitos de lesa humanidad debe hacerse en atención a la «circunstancia de que, no resultando in concreto aplicables las reglas sobre prescripción de la acción penal, ello debe extenderse a la regla específica de la prescripción gradual, en la medida en que su supuesto es —al igual que tratándose de la institución misma de la prescripción — la contingencia de la efectiva punición de los responsables» (2010: 234).

46. Por lo que se dirá, sorprende que la sentencia comentada disponga en el considerando decimoquinto: «Tampoco se advierte ninguna restricción constitucional, legal, de derecho convencional Internacional ni de ius cogens para su aplicación, desde que aquellas reglas sólo se limitan al efecto extintivo de la responsabilidad criminal» (el énfasis es nuestro).

47. Si bien «la base de ambas instituciones es el transcurso del tiempo», como indican González y otros (2014: 336), lo cierto es que nuestra legislación va un poco más allá: ese transcurso del tiempo que está en la base de ambas instituciones se sujeta a un plazo común. 
se estableció como data de la muerte de Guillermo Osvaldo Vallejo Ferdinand entre el 19 y el 22 de septiembre de 1973, fechas ciertas que permiten precisar el inicio del término que es necesario considerar para la procedencia de la institución que se analiza». El análisis culmina en el considerando decimosexto, donde precisa que se ha cumplido la mitad del término de prescripción del delito al tenor que sigue: «el lapso requerido para la procedencia de la institución cuestionada por los impugnantes ha transcurrido con creces».

La argucia, como puede apreciarse, consiste en atribuir al ilícito perseguido un plazo de prescripción que no le pertenece. Se trata de un homicidio calificado que en circunstancias ordinarias tiene asignada una pena de crimen a la que el artículo 94 del Código Penal le estipula un plazo de prescripción de 15 años. Pero ese término no es el correspondiente al delito que el mismo tribunal califica como imprescriptible: se ha utilizado un plazo prescriptivo base (de quince años) y su correspondiente mitad (siete años y medio), que no dice relación alguna con el crimen juzgado. Y lo anterior se debe a que la prescripción y la regla del artículo 103 del Código Penal se encuentran unidas, comparten idénticos fundamentos y su articulación se plasma en las diversas constelaciones normativas que el legislador reconoció al configurar el sistema -artículos 94, 96, 100, 369 quáter del Código Penal-. Al pretenderse lo contrario, dicha regla resulta inaplicable - según los propios requerimientos del artículo 103 del Código Penal-, a menos que, como lo hace el fallo comentado, se alteren los presupuestos materiales de la misma, atribuyéndole a un ilícito un plazo prescriptivo ajeno.

\section{Conclusiones}

1. El problema de delimitar la extensión de la prohibición que el derecho penal humanitario internacional imprime a los delitos de lesa humanidad y, en concreto, a si en dicho radio de veto se encuentra la media prescripción del artículo 103 del Código Penal, ha sido solucionado por la posición mayoritaria del fallo comentado en favor de la procedencia de este instituto ante ilícitos de la naturaleza referida.

2. Es efectivo que la prescripción y la media prescripción son instituciones distintas: la primera constituye una eximente de responsabilidad penal, en tanto que la segunda es una regla de determinación de la pena.

3. Pese a esta diferencia, los argumentos dados por la Corte Suprema como fundamentos diferenciadores de uno y otro instituto - y que a su vez, motivan la procedencia de la llamada «media prescripción en los delitos de lesa humanidad- no resultan dogmática, histórica y fácticamente correctos.

4. Tanto en la prescripción plena como en la parcial, de acuerdo a las disposiciones positivas que contienen el sistema prescriptivo, la justificación de ambos institutos se halla en la presunción de ausencia o disminución de necesidad de la pena, en razón 
de fines de prevención especial que, en abstracto, son asociados por el legislador al transcurso del tiempo.

5. La negación de este fundamento se materializa en la dificultad insorteable que presenta el razonamiento mayoritario del fallo comentado, y que consiste en la imposibilidad de cumplir con los requisitos legales de la denominada «media prescripción» - fundamentalmente su plazo—, y que es salvado por los juzgadores empleando antecedentes inexactos: atribuyen al ilícito un plazo que no le es propio, esto es, el que le correspondería en el caso de tratarse de un delito común y no de uno imprescriptible.

6. En definitiva, ambos institutos responden a los mismos fundamentos, difiriendosólo en los efectos que cada estatuto confiere al agente, lo que fue recogido por el legislador al punto de diseñar un sistema que funciona con una perfecta sincronía proporcional entre la prescripción y la regla del artículo 103 del Código Penal. Por ello, este reconocimiento en abstracto del estrecho vínculo en los fundamentos de ambas entidades, al ser desconocido por la Corte Suprema, indefectiblemente deviene en soluciones que, analizadas desde los requisitos legales de nuestro sistema prescriptivo, se apegan al derecho vigente sólo si les atribuyen presupuestos de hecho artificiosos, como en la especie lo es un plazo de prescripción «plena» que no pertenece al delito enjuiciado.

\section{Referencias}

Antón Oneca, José (1986). Derecho Penal. 2. ${ }^{a}$ edición. Madrid: Akal.

Bascuñán Rodríguez, Antonio (2007). «Derechos fundamentales y derecho penal». Revista de Estudios de la Justicia, 9: 47-74.

Bernales Rojas, Gerardo (2007). «La imprescriptibilidad de la acción penal en procesos por violaciones a los derechos humanos». Ius et Praxis, 13 (1): 245- 265.

Cabezas, Carlos (2013): «Prescripción de los delitos contra la indemnidad y libertad sexual de los menores de edad: Problemas aplicativos del artículo 369 quáter del Código Penal». Política Criminal, 8 (16): 386-407. Disponible en http://bit. ly/2sK18vE.

Cárdenas Aravena, Claudia (2014): «Los crímenes de lesa humanidad en el derecho chileno y en el derecho internacional. Sus requisitos comunes, además de referencias a los actos inhumanos en particular». Revista de Derecho (U. Austral de Valdivia), 27 (2): 169-189.

Centro de Derechos Humanos (2009): «Verdad y justicia: Las violaciones a los derechos humanos durante el régimen militar». Jorge Contesse Singh (director), Informe anual sobre derechos humanos en Chile 2009 (pp. 19-43). Santiago: Centro de Derechos Humanos, Universidad Diego Portales. 
Cury, Enrique (2005): Derecho Penal. Parte general. 7. edición. Santiago: Ediciones Universidad Católica de Chile.

Fernández NeIra, Karinna (2010). La prescripción gradual aplicada a los delitos de lesa humanidad. Tesis para optar al Grado de Magíster, Facultad de Derecho, Universidad de Chile, Santiago.

Fernández Neira, Karinna y Pietro Sferrazza (2009). «La aplicación de la prescripción gradual en casos de violaciones de derechos humanos». Revista de Estudios Constitucionales, 7 (1): 299-330.

Frister, Helmut (2011). Derecho Penal. Parte general. Trad. Marcelo Sancinetti. Buenos Aires: Hammurabi.

Garraud, René (1922). Traité théorique et practique du Droit Pénal Francaise. Tomo 2. París: Imprenta Sirey.

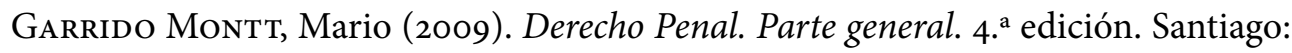
Jurídica.

González Ramírez, Isabel, Samuel Malamud Herrera; María Soledad Fuentealba Martínez y Florencio Pardo Montenegro (2014). «La media prescripción frente al delito de desaparición forzada de personas. ¿Incumplimiento de la normativa internacional en materia de crímenes de lesa humanidad?». Revista Direito GV, 10 (1): 321-346. Disponible en http://bit.ly/2tlGd52.

Groizard y Gómez De La Serna, Alejandro (1872). El Código Penal de 187o, concordado y comentado. Burgos: Imprenta de Timoteo Arnaiz.

Guzmán Dalbora, José Luis (2003). «Artículos 93 a 105, de la extinción de la responsabilidad penal». En Sergio Politoff y Luis Ortiz (dirs.), Texto y comentario del Código Penal chileno. Tomo 1. Santiago: Jurídica.

-. (2009). «Capítulo III». En Kai Ambos (coordinador), Desaparición forzada de personas. Análisis comparado e internacional (pp. 53-73). Bogotá: Nomos.

Jakoвs, Günther (1997): Derecho Penal. Parte general. Fundamentos y teoría de la imputación. 2. ${ }^{a}$ edición. Trad. de Joaquín Cuello Contreras y José Luis Serrano González De Murillo. Madrid: Marcial Pons.

Jescheck, Hans-Heinrich (1993). Tratado de Derecho Penal. Parte general. 4. ${ }^{a}$ edición. Granada: Comares.

Lazo, Santiago (1915). Los códigos chilenos anotados: Código Penal, orígenes, concordancias, jurisprudencia. Santiago: Poblete Cruzat Hnos. Editores.

Luzón PeÑa, Diego-Manuel (1995). «La relación del merecimiento de pena y de la necesidad de pena con la estructura del delito». En Jesús Silva Sánchez (editor en español) y Bernd Schünemann y Jorge de Figueiredo Dias (coords.) Fundamentos de un sistema europeo de derecho penal. Libro homenaje a Claus Roxin (pp. 115127). Barcelona: Bosch.

Mañalich, Juan Pablo (2010). Terror, pena y amnistía: El derecho penal ante el terrorismo de Estado. Santiago: Flandes Indiano. 
Matus Acuña, Jean Pierre (2012). «El fin de la doctrina Dolmestch». El Mercurio Legal, 30 de julio de 2012. Disponible en http://bit.ly/2t3uIPf.

-. (2005). «El informe Valech y la tortura masiva y sistemática como crimen contra la humanidad cometido en Chile durante el régimen militar. Su enjuiciamiento desde la perspectiva del derecho penal internacional». Ius Et Praxis (11) 1: 173-219.

Merkel, Adolf (1910). Derecho Penal. Trad. de P. Dorado. Madrid: La España Moderna.

Mezger, Edmund (1958). Derecho Penal. Parte general. 6. Edición. Trad. de Conrado A. Finzi. Buenos Aires: Bibliográfica.

Mir Puig, Santiago (2005). Derecho penal. Parte general. 7. edición. Barcelona: Reppertor.

Morrillas, Lorenzo (2013). «La función de la pena en el estado social y democrático de derecho». Revista Internacional de Doctrina y Jurisprudencia (Universidad de Almería, España), 4.

Muñoz Conde, Francisco y Mercedes García Arán (2004). Derecho Penal. Parte general. 6. ${ }^{\mathrm{a}}$ edición. Valencia: Tirant lo Blanch.

Náquira, Jaime, Cristóbal Izquierdo, Paulo Vial y Víctor Vidal (2008). «Principios y penas en el derecho penal chileno». Revista Electrónica de Ciencia Penal y Criminología, 10: 1-71. Disponible en http://bit.ly/2tZMXTq.

Nogueira, Humberto (2015). «Informe en derecho sobre precedentes jurisdiccionales en materia de media prescripción». Ius et Praxis, 14 (2): 561-589.

Politoff, Sergio, Jean Pierre Matus Acuña y María Cecilia Ramírez Guzmán (2009). Lecciones de Derecho Penal chileno. Parte general. Santiago: Editorial Jurídica de las Américas.

Prieto, Ana Luisa (1955). Causales de extinción de la responsabilidad criminal; perdón del ofendido, prescripción de la acción penal y de la pena. Memoria de Prueba para optar al Grado de Licenciado en la Facultad de Ciencias Jurídicas y Sociales de la Universidad de Chile, Editorial Universitaria, Santiago.

RAGUÉs, Ramón (2004). La prescripción penal: Fundamento y aplicación. Barcelona: Atelier.

Rivacoba y Rivacoba, Manuel (1974). Código Penal de la República de Chile; y Actas de las sesiones de la Comisión Redactora del Código Penal Chileno. Valparaíso: Edeval.

Roxin, Claus (1997). Derecho Penal. Parte general. Trad. y notas de Diego Luzón Peña, Miguel Díaz y García Conlledo y Javier de Vicente Remesal. Madrid: Civitas.

Silva Alliende, Matías (2011). «La situación del Decreto Ley de Amnistía después del fallo Almonacid Arellano». Persona y Sociedad (Universidad Alberto Hurtado), 25 (2): 125-140.

Silva SÁnchez, Jesús-María (2007). «La teoría de la determinación de la pena como sistema (dogmático): Un primer esbozo». Indret, 2: 1-15. 
VAN WeEZel, Alex (2007): «Inadmisibilidad de las 'leyes interpretativas' in malam partem en materia penal». Gaceta Jurídica, 323: 14-30.

Von Beling, Ernst (2002). Esquema de derecho penal. La doctrina del delito-tipo. Buenos Aires: Librería El Foro.

Welzel, Hans (1976). Derecho Penal alemán. Trad. de Juan Bustos Ramírez y Sergio Yáñez Pérez. 2. ${ }^{\text {a }}$ edición castellana. Santiago: Jurídica.

VIERA-Gallo, José y Valeria LÜвBERT (2012). «Los tratados sobre derechos humanos en la jurisprudencia chilena». Revista Estudios Internacionales, 44 (171): 87-115.

Yuseff Sotomayor, Gonzalo (2009). La prescripción penal. 3. ${ }^{a}$ edición. Santiago: Jurídica.

\section{Sobre el autor}

Francisco Javier Parra es abogado y candidato a doctorando en Derecho por la Universidad de Talca. Magíster en Derecho Penal por la Universidad de Talca y la Universidad Pompeu Fabra. Licenciado en Ciencias Jurídicas y Sociales por la Universidad de Concepción.Su correo electrónico es fparra@minpublico.cl. 